\title{
Regulation of forest defoliating insects through small mammal predation: reconsidering the mechanisms
}

\author{
Ida Kollberg • Helena Bylund • Otso Huitu • \\ Christer Björkman
}

Received: 6 November 2013 / Accepted: 3 September 2014 / Published online: 19 September 2014

(c) The Author(s) 2014. This article is published with open access at Springerlink.com

\begin{abstract}
Population densities of forest defoliating insects may be regulated by small mammal predation on the pupae. When outbreaks do occur, they often coincide with warm, dry weather and at barren forest sites. A proposed reason for this is that weather and habitat affect small mammal population density (numerical response) and hence pupal predation. We propose an alternative explanation: weather and habitat affect small mammal feeding behaviour (functional response) and hence the outbreak risks of forest pest insects. We report results from laboratory and field-enclosure experiments estimating rates of pupal predation by bank voles (Myodes glareolus) on an outbreak insect, the European pine sawfly (Neodiprion sertifer), at different temperatures $\left(15\right.$ and $20{ }^{\circ} \mathrm{C}$ ), in different microhabitats (sheltered and non-sheltered), and with or without access to alternative food (sunflower seeds). We found that the probability of a single pupa being eaten at $20{ }^{\circ} \mathrm{C}$ was lower than at $15{ }^{\circ} \mathrm{C}(0.49$ and 0.72 , respectively). Pupal predation was higher in the sheltered microhabitat than in the open one, and the behaviour of the voles differed between microhabitats. More pupae were eaten in situ in the sheltered microhabitat whereas in the open area more pupae were removed and eaten elsewhere. Access to alternative food did not affect pupal predation. The results suggest that predation rates on pine sawfly pupae by voles are influenced by temperature- and habitat-induced
\end{abstract}

Communicated by Wolf M. Mooij.

I. Kollberg $(\varangle) \cdot$ H. Bylund · C. Björkman

Department of Ecology, Swedish University of Agricultural

Sciences, Box 7044, 75007 Uppsala, Sweden

e-mail: ida.kollberg@slu.se

O. Huitu

Finnish Forest Research Institute (Metla), Suonenjoki, Finland variation in the physiology and behaviour of the predator, and not necessarily solely through effects on predator densities as previously proposed.

Keywords Herbivore $\cdot$ Functional response $\cdot$ Natural enemies $\cdot$ Outbreaks $\cdot$ Population dynamics

\section{Introduction}

The density of herbivorous insect populations is affected by mortality caused by different kinds of natural enemies. Mortality rates in predator-prey interactions are primarily determined by the density of the prey and the density of the predator (Holling 1961). The regulation of prey populations often requires predators to exhibit a numerical response as typically seen in specialist predators and parasitoids. Generalist predators normally do not show as strong a numerical response to a specific prey as specialist predators but their densities are rather influenced by the abundance of all prey in the habitat (Murdoch et al. 1985). Nonetheless, generalist predators have the capacity to regulate low-density insect populations through strong functional responses (Elkinton et al. 1996; Parry et al. 1997; Tanhuanpää et al. 1999). Thus, to understand how predation affects prey populations it is important to determine the type of predator involved and which mechanisms affect their numerical and functional responses.

Generalist small mammals have the potential to be involved in the regulatory process of forest defoliating insect populations because, among other food items, they feed on pupae buried in the ground (East 1974; Walsh 1990; Cook et al. 1994). For example, it has been suggested that small mammals-shrews, mice and voles-control populations of the forest pests the European pine sawfly 
(Neodiprion sertifer) and the gypsy moth (Lymantria dispar) during their endemic phases (Holling 1959; Hanski and Parviainen 1985; Olofsson 1987; Elkinton et al. 1996, but see Liebhold et al. 2000). But occasionally insect populations escape regulation and rapidly increase in density, resulting in what is commonly referred to as an 'outbreak'. One suggested explanation for forest defoliating insect outbreaks is a relaxation of the small mammal predation pressure on the pupae (Holling 1959; Hanski and Parviainen 1985).

It is widely acknowledged that forest insect densities are affected by weather, either due to direct effects on the herbivore (Neuvonen et al. 1999; Bale et al. 2002; Soubeyrand et al. 2008) or indirect effects through the host plant or natural enemies (Virtanen and Neuvonen 1999; Joern et al. 2006). However, the mechanisms behind how weather influences outbreak dynamics are not well understood. The anticipated role of climate in periodic insect outbreak species has been rejected since climatic variation is assumed to be of a more chaotic nature (Martinat 1987). Nevertheless, climate warming has led to the disruption of periodicity in some species, caused by not easily foreseen effects of biotic and abiotic interactions (Johnson et al. 2010). In species showing more irregular eruptive outbreak patterns, however, weather may play an important role for initiating outbreaks. Outbreaks of the European pine sawfly, for example, occur highly irregularly (Kolomiets et al. 1979) and often start after a series of warm and dry summers (McLeod 1970; Kolomiets et al. 1979). Although the association between weather and sawfly outbreaks has not been tested statistically due to lack of long-term data, it is generally believed that anomalies in weather are responsible for changes in insect abundances. A reason suggested for sawfly outbreaks is that warm and dry conditions lead to reduced reproduction in small mammals due to decreased access to food, which leads to lower densities and lower predation pressure on insect pupae (Pankakoski 1985; Hanski and Parviainen 1985). An alternative explanation is that temperature affects the metabolism of the small mammals and hence their appetite and functional response. Mammalian predators are likely to decrease their food intake when temperatures increase because they need less energy to maintain their body temperature (Sibly 1981). As an explanation for outbreaks, this modified small mammal predation hypothesis, suggesting that the functional responses are affected by changed environmental conditions, has not been tested.

Apart from the connection to weather conditions, it is also often observed that sawfly outbreaks occur in forests growing on nutrient-poor soils (McLeod 1970; Kolomiets et al. 1979). Again, the reason may be that the abundance of small mammals and hence the pupal predation pressure is influenced by forest type (Hanski and Parviainen 1985;
Herz and Heitland 2003). Forests on nutrient-rich sites are normally inhabited by larger populations of small mammals than forests on more impoverished sites (Hanski and Parviainen 1985), particularly during the critical low-density phase of the small mammal population cycle (Hansson 1969). Food resources are generally more abundant in rich forest habitats, and this has a direct positive influence on small mammal populations. A rich forest also usually contains more sheltering structures (Ecke et al. 2002), which small mammals use to escape predators (Kotler et al. 1991; Korpimäki et al. 1996).

It is also reasonable to assume that forest type affects the foraging activity of each predator individual. It is, for example, well known that microhabitat influences the foraging behaviour of small mammals (Kotler et al. 1991; Korpimäki et al. 1996) and that alternative food resources affect their foraging decisions (Elkinton et al. 2004). Two specific predictions can be made concerning patch quality and availability of food resources: individuals should stop foraging in a patch when the harvesting benefits fall below the foraging costs (Charnov 1976; Brown 1988); and predation on pupae should decrease when an alternative food source of higher quality is available (Holling 1965; Murdoch 1969). Hence, the structure of the forest floor in combination with availability of food resources may influence the foraging behaviour of small mammals significantly and, consequently, affect the predation pressure and influence the risk of outbreaks in certain insect species.

To summarise, we have identified three factors-temperature, microhabitat and alternative food sources-with the potential to affect the functional response of small mammals through changes in their metabolism and feeding behaviour. To quantify how these factors affect the predation rates of small mammals, we conducted laboratory experiments at two temperatures to study the metabolic effect, and experiments in field enclosures to evaluate the role of microhabitat and alternative food on vole behaviour. As model species we used the European pine sawfly (Neodiprion sertifer) which is one of the most well-studied outbreak insect species and on which many of the original empirical studies and theoretical papers about outbreaks are based, and the bank vole (Myodes glareolus) a known predator of $N$. sertifer. The hypotheses tested were:

1. Predation by voles on sawfly pupae is inversely related to temperature.

2. Voles prefer to occupy and consume prey in sheltered, 'non-risky', microhabitats as compared to open, 'risky', habitats.

3. When voles have access to alternative food, pupal predation is more reduced in open habitats than in sheltered habitats. 
The aim of the study was to increase our knowledge of how temperature and habitat conditions affect the rate of pupal predation by small mammals and hence the likelihood of pine sawfly outbreaks.

\section{Materials and methods}

\section{Study species}

The European pine sawfly, Neodiprion sertifer Geoffr. (Hymenoptera: Diprionidae), is a univoltine outbreak species that feeds on pine (Pinus spp.). The larvae are gregarious and feed primarily on older needles in the summer (June-July in Fennoscandia). After finishing feeding, the larvae drop to the ground and spin a cocoon in the upper humus layer, often within the crown projection of the tree (Kolomiets et al. 1979). The larvae pupate within the cocoon and adults emerge after about 2 months (Wallace and Sullivan 1963). Sawfly cocoons for the experiment were collected from outbreak populations in southern Sweden by caging larvae in their later instars and allowing them to pupate and spin cocoons within the cage. Cocoons used in the temperature (laboratory) and microhabitat (field enclosure) experiments were collected in summer 2011 from one outbreak area $\left(57^{\circ} 38^{\prime} \mathrm{N}, 15^{\circ} 93^{\prime} \mathrm{E}\right)$ while cocoons used in the alternative food (field-enclosure) experiment were collected in summer 2012 from another outbreak area $\left(57^{\circ} 37^{\prime} \mathrm{N}, 16^{\circ} 14^{\prime} \mathrm{E}\right)$. In the experiments, the cocoons were mixed and randomly distributed between the experimental units. The cocoons were kept frozen to prevent the sawflies from hatching. A small study was conducted to investigate whether freezing affected the predation risk, and we found no difference in disappearance between previously frozen and non-frozen cocoons $\left(\chi^{2}=0.78, d f=1, p=0.38\right)$. In the method study, one frozen and one unfrozen cocoon were buried $1 \mathrm{~cm}$ in the soil at each side of a thin wooden stick at a distance of 1, 1.5, 2, 2.5 and $3 \mathrm{~m}$ from each of eight pine trees growing in a young stand (approximately 15 years) outside Uppsala, Sweden, i.e. 40 pairs of frozen and unfrozen cocoons. After 3 weeks the soil around the sticks was searched for cocoons and if not found they were considered predated.

The main predators in the pupal stage are small mammals, including voles and shrews, but birds and the larvae of click beetles (Elateridae) are also known predators. In our experiments we used bank voles (Myodes glareolus Schreber). The bank vole is the most common vole species in lowland forests in Fennoscandia. Their diet consists typically of vegetable matter but also includes animal material (Hansson 1985; Viro and Sulkava 1985). Like all endotherms, voles have a temperature optimum when the maintenance of body temperature requires least energy. The thermoneutral zone for bank voles is between 25 and $30{ }^{\circ} \mathrm{C}$ (Aalto et al. 1993). The experimental voles were born in the laboratory of the Suonenjoki research station of the Finnish Forest Research Institute (FFRI), and housed for 3-8 months in groups of two to four in maintenance cages $(60 \times 38 \times 20 \mathrm{~cm}$; Tecniplast, Italy $)$ prior to the experiments. During the maintenance period, voles were provided with rodent laboratory pellets (Altromin 1314F; Altromin Spezialfutter, Germany) and water ad libitum, and turnip and apple pieces intermittently. All voles selected for the experiments had a body mass in the range 20-30 g, and represented a roughly equal sex ratio. For each replicate in all three experiments a new vole was used, i.e. each vole individual was only used once.

\section{Temperature experiment}

To evaluate the effect of temperature on bank vole predation rates of sawfly pupae, a laboratory experiment was set up in a climate room at the FFRI Suonenjoki field research station in Finland $\left(62^{\circ} 38^{\prime} \mathrm{N}, 27^{\circ} 7^{\prime} \mathrm{E}\right)$. The temperature was kept constant at either 15 or $20^{\circ} \mathrm{C}$, with a light period of $16 \mathrm{~h}$ light, $8 \mathrm{~h}$ dark. The lower temperature treatment was chosen to reflect the daily mean air temperature for the period that sawflies are naturally pupae. The $20{ }^{\circ} \mathrm{C}$ temperature treatment was chosen to reflect exceptionally warm temperatures.

Experimental cages (same specifications as the maintenance cages) were fitted with a chipboard tray with 24 nails $(7 \mathrm{~cm})$ protruding upwards from the bottom, spaced evenly in a $4 \times 6$ configuration at $6-\mathrm{cm}$ intervals. The tray was covered with a $2-\mathrm{cm}$ layer of sand, onto which 24 cocoons were placed singly at the base of each nail to facilitate relocation. All cocoons were then covered with a 2-cm layer of damp peat. An additional two cocoons were placed centrally on top of the peat to condition the voles to prey on them. A water bottle was attached to the cage and cotton wool added to provide nesting material.

The voles were placed singly in smaller cages $(43 \times 26 \times 15 \mathrm{~cm}$; Tecniplast) in the climate room 5 days before the experiment took place in order to acclimatise them to their new environment. During the acclimatization period the voles had free access to food (pellets and turnip) and water but when the experiment started and the voles were transferred to the experimental cage, this food was taken away. The voles were left in the experimental cages for $22 \mathrm{~h}$ (i.e. one feeding trial) and were then removed and transferred back into their maintenance cages. Cocoons were thereafter categorised as intact or empty. The experiment was repeated over four feeding trials for each temperature with six to 12 cages at a time; in total there were 34 replicates at $15^{\circ} \mathrm{C}$ and 42 replicates at $20{ }^{\circ} \mathrm{C}$. 
Microhabitat experiment

The effect of microhabitat on the pupal predation by voles was investigated in $3 \times 3$-m outdoor enclosures at the FFRI Suonenjoki field research station in Finland $\left(62^{\circ} 38^{\prime} \mathrm{N}\right.$, $27^{\circ} 7^{\prime} \mathrm{E}$ ). The enclosures were constructed of sheet metal extending $60 \mathrm{~cm}$ both below and above ground and protected with a $10-\mathrm{cm}$-mesh plastic net to prevent bird predation. A sheet metal shelter $(40 \times 40 \times 40 \mathrm{~cm})$ was located in the middle of each enclosure, and voles had access to this at all time. Half the area of each enclosure was prepared so that it was open and hostile; this was achieved by spreading a layer of soil over the short cut grass (to ca. $5-\mathrm{cm}$ height) that covered the ground within the enclosure. In the other half of the enclosure branches and hay were spread out (over approximately two-thirds of the enclosure floor) to represent a rich habitat with a lot of structures providing shelter. One bank vole of random sex was placed into each enclosure 2 days before the experiment started, together with $0.5 \mathrm{dl}$ of laboratory pellets. The experiment began by first removing all remaining pellets and thereafter placing two trays with 24 nails (like the ones in the temperature experiment) prepared with the same number of cocoons, one in each of the artificial microhabitats (Fig. 1a). The tray in the sheltered area was covered by a $2-\mathrm{mm}$ metal wire mesh resting on the nails to enable branches to be placed over the tray without disturbing the tray surface. The voles were allowed to feed for $22 \mathrm{~h}$. After the experimental period, the trays were collected and cocoons were categorised as intact or empty, as in the temperature experiment. We also added a third category: lost cocoons, i.e. ones that we could not find. In the field small mammals commonly move the cocoons from where found to store them elsewhere for later consumption
(Buckner 1955). Lost cocoons together with the cocoons categorised as empty, were considered to be predated. The experiment was repeated in two feeding trials, on 16 and 21 September 2011. In the first trial, ten enclosures were used and in the second, 12 .

\section{Alternative food experiment}

The effect of alternative food was investigated in the same outdoor enclosures as in the microhabitat experiment. The difference was that for this experiment an enclosure was either completely open or completely sheltered, and either with or without an alternative food source (i.e. there were four treatments; Fig. 1b). Cocoons were presented in two trays per enclosure as in the microhabitat experiment. The alternative food, sunflower seeds, was presented in six Petri dishes (diameter $90 \mathrm{~mm}$ ) spread evenly around the enclosure. Each dish contained four sunflower seeds (a total of 24 seeds per enclosure) laid on a layer of sand and lightly covered with a thin layer of peat. The voles were acclimatised in the enclosures for 2 days before the experiment was started, as in the microhabitat experiment. The voles were allowed to feed on the pupae for $19 \mathrm{~h}$, after which intact, empty and lost cocoons were recorded, as were remaining seeds. The experiment was repeated in three feeding trials, beginning on 2, 6 and 15 October 2012. In the first trial 18 enclosures were used with four to five replicates of each treatment, in the second trial 15 enclosures were used with two to five replicates per treatment and in the third trial 14 enclosures were used with three to four replicates per treatment. The reason for the uneven replicate sizes was that at some occasions the vole had died and those replicates were therefore not included.
Fig. 1 Schematic view of the study design for estimating pupal predation of Neodiprion sertifer by bank voles. In the microhabitat experiment the bank voles had access to both a sheltered and an open microhabitat (a). In the alternative food experiment the voles were assigned to one of the microhabitats, with or without access to sunflower seeds (b)
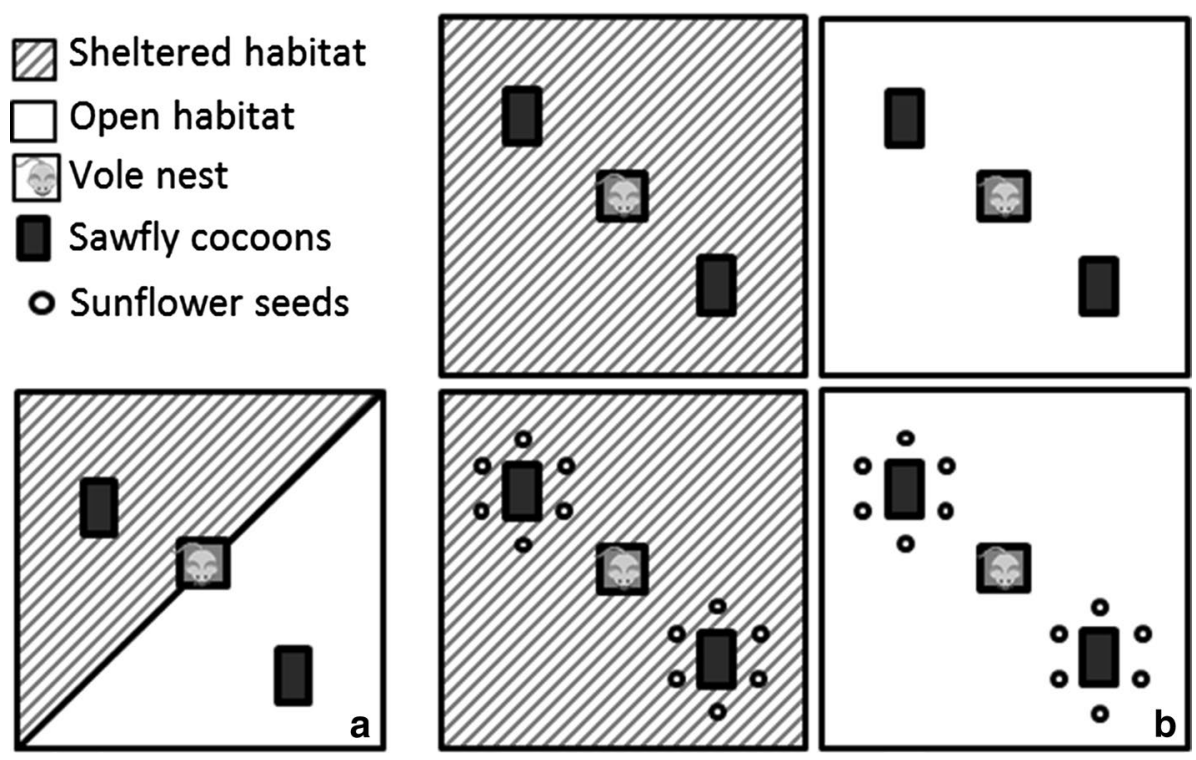
Data analysis

To evaluate the effect of temperature on predation rate, the probability of the pupae being eaten was analysed. To quantify the effect of microhabitat and alternative food on predation rate, the probabilities of the pupae being eaten or lost were first analysed separately and then added together for analysis, since both empty and lost cocoons were considered to be predated. In each analysis, numbers of empty, lost or predated cocoons were used as binary variables (e.g. empty cocoons, not empty cocoons) and analysed with logistic regression models with logit link in the R software [the generalised linear model $(\mathrm{glm})$ function, version 2.15.1; R Development Core Team 2012]. Due to overdispersion in the data (residual deviance larger than residual $d f$ ) a quasi-binomial distribution was used. In the temperature experiment, temperature and vole sex were used as the explanatory variables in the full model. In the microhabitat experiment, habitat (sheltered/open area), vole sex and trial were used as explanatory variables in the full model. In the alternative food experiment, access to alternative food (yes/no), habitat (sheltered/open), vole sex and trial were used as explanatory variables in the full model. Trial was treated as a fixed factor since the number of trials (two and three, respectively) is too low to be meaningful as a random effect. Explanatory terms in the models were reduced by backward selection starting from the full model with interactions, dropping non-significant terms (at $\alpha=0.05$ ) one by one until the model only contained significant effects.

\section{Results}

Temperature experiment

More pupae were eaten at $15{ }^{\circ} \mathrm{C}$ than at $20^{\circ} \mathrm{C}$ (Fig. 2). The probability $( \pm \mathrm{SE})$ of a pupa being eaten by a bank vole was $0.72(0.65-0.78)$ at $15{ }^{\circ} \mathrm{C}$ compared to $0.49(0.43-0.55)$ at $20{ }^{\circ} \mathrm{C}$ (likelihood-ratio $\chi^{2}=6.7, n=76, p=0.01$ ).

Microhabitat experiment

In the sheltered area $75 \pm 6 \%$ (mean $\pm \mathrm{SE}$ ) of the cocoons were either empty or lost as compared to $60 \pm 6 \%$ in the open area. However, the outcome was influenced by trial (Table 1; Fig. 3a). In the first trial the probability of being predated was higher in the sheltered area (separate GLM for trial $1 ; t=-3.6, d f=19, p=0.002$ ) whereas in the second trial there was no difference (separate GLM for trial $2 ; t=0.3, d f=23, p=0.76$ ). The lowest probability of being predated (0.49) was found in the open area during the first trial. In the sheltered area most of the pupae (82-93\%) were eaten by the voles in situ, while in the open area half

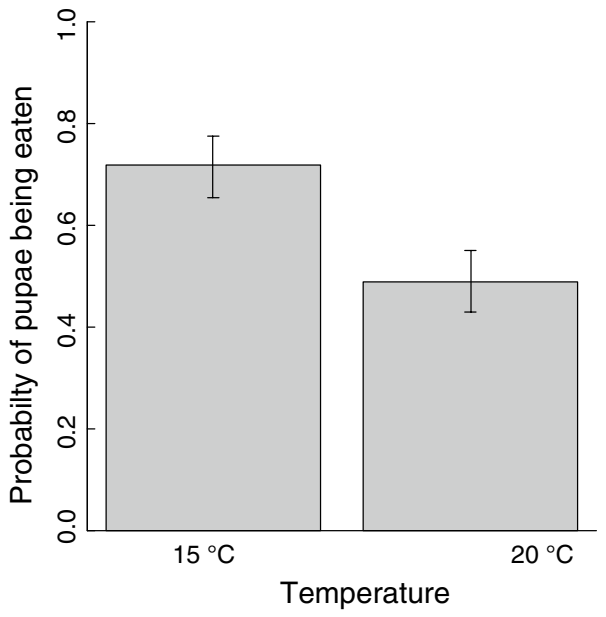

Fig. 2 The probability ( \pm SE) of sawfly pupae (Neodiprion sertifer) being eaten by bank voles at 15 and $20{ }^{\circ} \mathrm{C}$

Table 1 Analysis of deviance table for generalised linear models of the probability of Neodiprion sertifer pupae being eaten, lost or predated (i.e. eaten + lost) by bank voles from a microhabitat experiment

\begin{tabular}{lccc}
\hline & $\chi^{2}$ & $d f$ & $P$-value \\
\hline Eaten & & & \\
Habitat & 15.48 & 1 & $<0.001$ \\
Trial & 0.57 & 1 & 0.45 \\
Habitat $\times$ trial & 5.5 & 1 & 0.02 \\
Lost & & & \\
Habitat & 9.88 & 1 & $<0.01$ \\
Predated & & & \\
Habitat & 3.30 & 1 & 0.07 \\
Trial & 0.02 & 1 & 0.88 \\
Habitat $\times$ trial & 6.59 & 1 & 0.01 \\
\hline
\end{tabular}

Explanatory variables in the full models were microhabitat (open/ sheltered), feeding trial and vole sex. Results presented are from reduced models, i.e. if the interaction term was significant values are presented for all variables, if not values are only presented for significant main factors

of the pupae (46-48\%) were removed from the unsheltered area to be consumed elsewhere (Table 1; Fig. 3a).

The weather conditions differed between the trials. The daily mean temperature was $11.2{ }^{\circ} \mathrm{C}$ and there was a total rainfall of $0.4 \mathrm{~mm}$ during the first trial; during the second trial the mean temperature was $10.2^{\circ} \mathrm{C}$ but the total rainfall amounted to $13.2 \mathrm{~mm}$.

\section{Alternative food experiment}

In 19 out of 24 enclosures in which the sunflower seeds had been added, all the seeds were eaten from the petri 

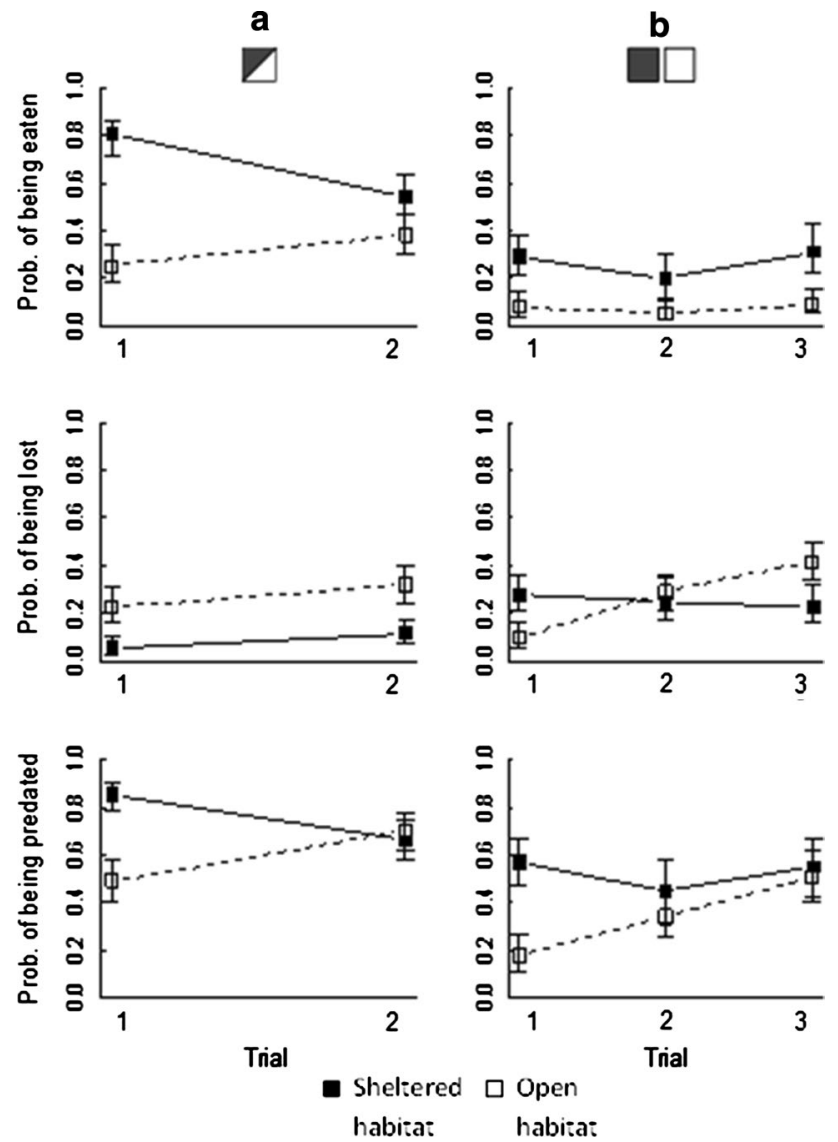

Fig. 3 The probability ( \pm SE) of sawfly pupae (Neodiprion sertifer) being eaten, lost or predated by bank voles in different microhabitats (covered or open area) and feeding trials $(1,2,3)$. Predated pupae were either eaten in situ or lost. Left-hand figure parts (a) describe feeding behaviour when the voles could choose between the covered and open areas; right-hand figure parts (b) show data relating to a situation where the voles had no choice

dishes. However, access to alternative food did not affect predation on pupae $\left(\chi^{2}=0.002, d f=1, p=0.96\right)$. In the sheltered habitat $53 \pm 7 \%$ (mean \pm SE) of the pupae (i.e. eaten and lost cocoons combined) were predated compared to only $34 \pm 6 \%$ in the open habitat (Table 2; Fig. 3b). Of the predated pupae, $51 \%$ were eaten in situ in the sheltered microhabitat compared to $21 \%$ in the open area. There was no general effect of habitat type on the number of lost cocoons. However, the number of cocoons that were removed in the open habitat but not in the covered differed between trials (Table 2; Fig. 3b).

During the first trial in the alternative food experiment, the daily mean temperature was $10.8^{\circ} \mathrm{C}$ and the sky mostly clear (1.8-mm rainfall); during the second trial, the temperature was $6.7^{\circ} \mathrm{C}$ and there was $6.9 \mathrm{~mm}$ of rain; during the third trial the temperature was $4.4{ }^{\circ} \mathrm{C}$ and there was $13.4 \mathrm{~mm}$ of rain.
Table 2 Analysis of deviance table for generalised linear models of the probability of Neodiprion sertifer pupae being eaten, lost or predated (i.e. eaten + lost) by bank voles from an alternative food experiment

\begin{tabular}{llll}
\hline & $\chi^{2}$ & $d f$ & $P$ value \\
\hline Eaten & 12.7 & 1 & $<0.001$ \\
$\quad$ Habitat & & & \\
Lost & 0.01 & 1 & 0.93 \\
Habitat & 3.95 & 2 & 0.14 \\
Trial & 6.82 & 2 & 0.03 \\
Habitat $\times$ trial & & & 0.04 \\
Predated & 4.38 & 1 & \\
Habitat &
\end{tabular}

Explanatory variables in the full models were microhabitat (open/ sheltered), feeding trial, access to alternative food (yes/no) and vole sex. Results presented are from reduced models, i.e. if the interaction term was significant values are presented for all variables, if not values are only presented for significant main factors

\section{Discussion}

The results suggest that predation of pine sawfly pupae by voles is lower at higher temperatures and in barren forests due to physiological and behavioural causes affecting the functional response, and not necessarily solely through effects on predator densities as previously proposed (Hanski and Parviainen 1985; Hanski 1987). More specifically, the temperature experiment in this study clearly showed that voles preyed less on $N$. sertifer pupae when exposed to the warmer temperature treatment $\left(20{ }^{\circ} \mathrm{C}\right)$. This is expected, because small mammals respond to an increase in temperature by lowering their metabolism which reduces their demand for food (Sibly 1981). Small mammals have been shown to have lower reproductive success and, as a consequence, lower population densities during warm and dry summers (Pankakoski 1985; Lewellen and Vessey 1998). The occurrence of pine sawfly outbreaks has been explained by such decreases in small mammal populations, which leads to weaker top-down control (Hanski and Parviainen 1985). Our results indicate that also reduced predation pressure on pupae in warmer temperatures, regardless of changes in small mammal density, could add to a higher survival of pine sawflies, contributing to the initiation of an outbreak.

The predation risk-allocation hypothesis (Lima and Bednekoff 1999), supported by most studies on the topic (Verdolin 2006), states that animals should forage more in low-risk situations than in high-risk situations. Animals should stop foraging in a patch when the harvesting benefits fall below the energetic costs and the risk of being killed (Charnov 1976; Brown 1988). Only when the urge for food becomes great enough would animals be forced to forage in 
high-risk situations or locations. In our outdoor experiments in which we had simulated low- and high-risk situations, we found support for this hypothesis, although the differences in predation rates between the covered and open areas were smaller than expected. When given a choice, as in the microhabitat experiment, one would expect voles to deplete the resources in the sheltered habitat before venturing out into the risky open area (e.g. Kotler et al. 1991; Jacob and Brown 2000). It is plausible that the relative proximity of cocoons in the open area to the covered area led voles not to experience the open area, a high-risk habitat. However, the voles behaved differently in the different microhabitats. In the covered area more pupae were eaten in situ whereas in the open area more cocoons were removed. In a situation when the voles did not have a choice, as in the alternative food experiment, there was no general difference in the number of cocoons removed between habitats.

Although the outdoor experiment was not designed to study the effects of climatic factors on pupae predation rates, our results do identify weather as a potentially important factor. Interestingly, and for reasons that we can only speculate about, trial was a significant factor in both outdoor experiments. It is likely that weather during experimental trials influence the behaviour of voles (Doucet and Bider 1974; Vickery and Rivest 1992), and that rain has a greater effect than temperature. During trials with clear sky, pupal predation was higher in the covered area compared to the open area, whereas during trials with rain there was no difference. Our interpretation of these results is that a sheltered habitat is always a relatively good habitat for voles to feed in but that weather (i.e. precipitation) influences the propensity of voles to enter open habitats for foraging. Voles may feel more secure during rainfall because their natural enemies (e.g. birds of prey and weasels) are less active and/or efficient when it rains or when the illumination decreases due to cloud cover (Kotler et al. 1991). If so, weather in combination with habitat, may have a strong impact on pupal predation and deserve further studies.

According to optimal foraging theory, the best strategy for a generalist predator would be to specialise on, and whenever necessary switch to, the most profitable food source (Stephens and Krebs 1986). The role of alternative food as an influential component of population dynamics in predator-prey systems has received much attention (Murdoch 1969; Angelstam et al. 1984). In general, pupal predation per individual may decrease when small mammals are offered an alternative food source of higher quality (Murdoch 1969; Elkinton et al. 2004). We did not find support for the hypothesis that, in the open habitat, pupal predation would decrease more than in the sheltered habitat when alternative food in the form of seeds were also available. In fact, there was no difference in the number of predated pupae between enclosures with or without seeds. Although the relative preference of voles for seeds vs. pupae is not established, in most of the cases all the seeds had been eaten, suggesting vole preference for the seeds. Probably, the voles concentrated on these before searching for the pupae. In the 'rich' habitat however, voles ate more food in total, since they consumed both pupae and seeds. A high diversity and abundance of food within a vole's home range may enhance their feeding activity.

The cause of outbreaks in forest insect pests might be explained by weakened top-down predatory control due to decreases in small mammal population densities caused by weather, microhabitat and/or food supply (Hanski and Parviainen 1985). In this study we demonstrate that each of these factors also can explain variation in predator behaviour and predation rates without there being changes in predator densities. In combination with temperature-triggered physiological responses, such as altered metabolism, changes in behaviour related to microhabitat could be a potential contributor to the onset of outbreaks of defoliators which pupate in the ground. We acknowledge, however, that other factors interacting with forest insects may be affected by weather and microhabitat and thereby play a role for outbreak dynamics, for example host plant quality (White 1974; Larsson and Tenow 1984; Mattson and Haack 1987). In general, our ability to predict future events such as insect outbreaks largely depends on how well we understand mechanistic interactions between different trophic levels and the dynamics of populations and communities. The results presented here highlight that in order to relate observed patterns in prey population dynamics in nature to putative mechanisms, involving natural enemies, one needs to evaluate not only changes in densities but also behavioural responses of the enemies to the biotic and abiotic environment.

Acknowledgments We thank Anaiis Zimmer and Aitor Lopez for assistance in the lab and field. We are also grateful to Stig Larsson and Diana Rubene who provided thoughtful comments on the manuscript and to Mikael Andersson Franko for statistical consultancy. The study was financed by FORMAS, the Mistra program Future Forests, the EU project BACCARA, and the Academy of Finland (grant 133495 to O. H.).

Open Access This article is distributed under the terms of the Creative Commons Attribution License which permits any use, distribution, and reproduction in any medium, provided the original author(s) and the source are credited.

\section{References}

Aalto M, Górecki A, Meczeva R, Wallgren H, Weiner J (1993) Metabolic rates of the bank voles (Clethrionomys glareolus) in Europe along a latitudinal gradient from Lapland to Bulgaria. Ann Zool Fenn 30:233-238

Angelstam P, Lindström E, Widén P (1984) Role of predation in short-term population fluctuations of some birds and mammals in Fennoscandia. Oecologia 62:199-208 
Bale JS, Masters GJ, Hodkinson ID, Awmack C, Bezemer TM, Brown VK, Butterfield J, Buse A, Coulson JC, Farrar J, Good JEG, Harrington R, Hartley S, Jones TH, Lindroth RL, Press MCc, Symrnioudis I, Watt AD, Whittaker JB (2002) Herbivory in global climate change research: direct effects of rising temperatures on insect herbivores. Glob Change Biol 8:1-16

Brown JS (1988) Patch use as an indicator of habitat preference, predation risk, and competition. Behav Ecol Sociobiol 22:37-47

Buckner CH (1955) Small mammals as predators of sawflies. Can Entomol 87:121-123

Charnov EL (1976) Optimal foraging: the marginal value theorem. Theor Popul Biol 9:129-136

Cook SP, Hain FP, Smith HR (1994) Oviposition and pupal survival of gypsy moth (Lepidoptera: lymantriidae) in Virginia and North Carolina pine-hardwood forests. Environ Entomol 23:360-366

Doucet GJ, Bider JR (1974) The effect of weather on the activity of the masked shrew. J Mammal 55:348-363

East R (1974) Predation on the soil-dwelling stages of the winter moth at Wytham woods. J Anim Ecol 43:611-626

Ecke F, Löfgren O, Sörlin D (2002) Population dynamics of small mammals in relation to forest age and structural habitat factors in northern Sweden. J Appl Ecol 39:781-792

Elkinton JS, Healy WM, Buonaccorsi JP, Boettner GH, Hazzard AM, Smith HR, Liebhold AM (1996) Interactions among gypsy moths, white-footed mice, and acorns. Ecology 77:2332-2342

Elkinton JS, Liebhold AM, Muzika RM (2004) Effects of alternative prey on predation by small mammals on gypsy moth pupae. Popul Ecol 46:171-178

Hanski I (1987) Pine sawfly population dynamics: patterns, processes, problems. Oikos 50:327-335

Hanski I, Parviainen P (1985) Cocoon predation by small mammals, and pine sawfly population dynamics. Oikos 45:125-136

Hansson L (1969) Spring populations of small mammals in central Swedish Lapland in 1964-68. Oikos 20:431-450

Hansson L (1985) The food of bank voles, wood mice and yellow-necked mice. In: Flowerdew JR, Gurnell J, Gipps JHW (eds) The ecology of woodland rodents: bank voles and wood mice: the proceedings of the symposium held at the Zoological Society of London on 23rd and 24th of November 1984. Clarendon, Oxford, pp 141-168

Herz A, Heitland W (2003) Impact of cocoon predation and parasitism on endemic populations of the common pine sawfly, Diprion pini (L.) (Hymenoptera, Diprionidae) in different forest types. Agric For Entomol 5:35-41

Holling CS (1959) The components of predation as revealed by a study of small mammal predation of the European pine sawfly. Can Entomol 91:293-320

Holling CS (1961) Principles of insect predation. Annu Rev Entomol 6:163-182

Holling CS (1965) The functional response of predators to prey density and its role in mimicry and population regulation. Mem Entomol Soc Can 45:3-60

Jacob J, Brown JS (2000) Microhabitat use, giving-up densities and temporal activity as short- and long-term anti-predator behaviors in common voles. Oikos 91:131-138

Joern A, Danner BJ, Logan JD, Wolesensky W (2006) Natural history of mass-action in predator-prey models: a case study from wolf spiders and grasshoppers. Am Midl Nat 156:52-64

Johnson DM, Büntgen U, Frank DC, Kausrud K, Haynes KJ, Liebhold AM, Esper J, Stenseth NC (2010) Climate warming disrupts recurrent Alpine insect outbreaks. PNAS 107:20576-20581

Kolomiets NG, Stadnitskii GV, Vorontzov AI (1979) The European pine sawfly. Amerind, New Delhi

Korpimäki E, Koivunen V, Hakkarainen H (1996) Microhabitat use and behavior of voles under weasel and raptor predation risk: predator facilitation? Behav Ecol 1:30-34
Kotler BP, Brown JS, Hasson O (1991) Factors affecting gerbil foraging behaviour and rates of owl predation. Ecology 72:2249-2260

Larsson S, Tenow O (1984) Areal distribution of a Neodiprion sertifer (Hym., Diprionidae) outbreak on Scots pine as related to stand condition. Holarct Ecol 7:81-90

Lewellen RH, Vessey SH (1998) Modeling biotic and abiotic influences on population size in small mammals. Oecologia 113:210-218

Liebhold AM, Elkinton JS, Williams D, Muzika RM (2000) What causes outbreaks of the gypsy moth in North America? Popul Ecol 42:257-266

Lima SL, Bednekoff PA (1999) Temporal variation in danger drives antipredator behaviour: the predation risk allocation hypothesis. Am Nat 153:649-659

Martinat PJ (1987) The role of climatic variation and weather in forest insect outbreaks. In: Barbosa P, Schultz JC (eds) insect outbreaks. Academic Press, London, pp 241-268

Mattson WJ, Haack RA (1987) The role of drought in outbreaks of plant-eating insects. Bioscience 37:110-118

McLeod JM (1970) The epidemiology of the Swaine jack-pine sawfly, Neodiprion swainei Midd. For Chron 46:126-133

Murdoch WW (1969) Switching in general predators: experiment on predator specificity and stability of prey populations. Ecol Monogr 39:335-354

Murdoch WW, Chesson J, Chesson PL (1985) Biological control in theory and practice. Am Nat 125:344-366

Neuvonen S, Niemelä P, Virtanen T (1999) Climate change and insect outbreaks in boreal forests: the role of winter temperatures. Ecol Bull 47:63-67

Olofsson E (1987) Mortality factors in a population of Neodiprion sertifer (Hymenoptera: diprionidae). Oikos 48:297-303

Pankakoski E (1985) Relationship between some meteorological factors and population dynamics of Sorex araneus in southern Finland. Acta Zool Fenn 173:287-289

Parry D, Spence J, Volney W (1997) Response of natural enemies to experimentally increased populations of the forest tent caterpillar, Malacosoma disstria. Ecol Entomol 22:97-108

R Development Core Team (2012) R: A language and environment for statistical computing. R Foundation for Statistical Computing, Vienna

Sibly RM (1981) Strategies in digestion and defecation. In: Townsend CR, Calow P (eds) Physiological ecology: an evolutionary approach to resourse use. Sinauer, Sunderland, pp 109-139

Soubeyrand S, Neuvonen S, Penttinen A (2008) Mechanical-statistical modeling in ecology: from outbreak detections to pest dynamics. B Math Biol 71:318-338

Stephens DW, Krebs JR (1986) Foraging theory. Princeton University Press, Princeton

Tanhuanpää M, Ruohomäki K, Kaitaniemi P, Klemola T (1999) Different impact of pupal predation on populations of Epirrita autumnata (Lepidoptera; Geometridae) within and outside the outbreak range. J Anim Ecol 68:562-570

Verdolin JL (2006) Meta-analysis of foraging and predation risk tradeoffs in terrestrial systems. Behav Ecol Sociobiol 60:457-464

Vickery WL, Rivest D (1992) The influence of weather on habitat use by small mammals. Ecography 15:205-211

Viro P, Sulkava S (1985) Food of the bank vole in Northern Finnish spruce forests. Acta Theriol 30:259-266

Virtanen T, Neuvonen S (1999) Performance of moth larvae on birch in relation to altitude, climate, host quality and parasitoids. Oecologia 120:92-101

Wallace DR, Sullivan CR (1963) Laboratory and field investigation of the effect of temperature on the development of Neodiprion sertifer (Geoffr.) in the cocoon. Can Entomol 95:1051-1066 
Walsh PJ (1990) Site factors, predators and pine beauty moth mortality. In: Watt AD, Leather SR, Hunder MD, Kidd NAC (eds) Population dynamics of forest insects. Intercept, Hampshire, pp 245-252
White TCR (1974) A hypothesis to explain outbreaks of looper caterpillars, with special reference to populations of Selidosema suavis in a plantation of Pinus radiata in New Zealand. Oecologia 16:279-301 